\title{
OPTIMALISASI PENGGUNAAN INPUT USAHATANI BAWANG MERAH DI DESA SUNGAI GERINGGING KECAMATAN KAMPAR KIRI KABUPATEN KAMPAR PROPINSI RIAU
}

\section{Optimization of the Use Shallot Input in Sungai Geringging Village Kampar Kiri District Kampar Regency of Riau Province}

\author{
Sri Ayu Kurniati dan Darus \\ Fakultas Pertanian Universitas Islam Riau. Jl. Kaharuddin Nasution 113, Pekanbaru 28284 Riau \\ Telp. : 0761-72126 ext. 123, Fax : 0761-674681 \\ [Diterima: November 2018; Disetujui: Desember 2018]
}

\begin{abstract}
Shallots are a strategic commodity but still require attention in the use of optimal inputs to achieve maximum results. All farm inputs are still limited in number while high production is highly expected by farmers. The purpose of this study was to determine the use of inputs, analyze the use of inputs in order to achieve optimal conditions and analyze the effect of input price changes on the optimal solution on red onion farming in Sungai Geringging Village, Kampar Kiri District, Kampar Regency. Descriptive qualitative and quantitative analysis methods using Linear Programming. The results of input use research state that the area of the land is narrow that is an average of 0.25 hectares, the seeds are superior but the number of uses is still below standard, more use of labor outside the family, dominant farmers use inorganic fertilizers, use pesticides to repel pests and work equipment simple one. The use of farming inputs is not optimal so that the reduction or addition of input availability will not affect the total profit in optimal conditions. The effect of changes when an input price increases and decreases by 3.25 percent does not show a difference when compared to the initial optimal conditions.
\end{abstract}

Keywords: Optimization, Input, Shallot, Linear Programming, LINDO

\begin{abstract}
ABSTRAK
Bawang merah merupakan komoditas strategis namun masih memerlukan perhatian dalam penggunaan input yang optimal untuk mencapai hasil yang maksimal. Semua input usahatani masih terbatas jumlahnya sementara produksi tinggi sangat diharapkan oleh petani. Tujuan penelitian ini adalah untuk mengetahui penggunaan input, menganalisis penggunaan input agar tercapai kondisi optimal dan menganalisis pengaruh perubahan harga input terhadap solusi optimal pada usahatani bawang merah di Desa Sungai Geringging Kecamatan Kampar Kiri Kabupaten Kampar. Metode analisis secara deskriptif kualitatif dan kuantitatif menggunakan Linear Programming. Hasil penelitian penggunaan input menyatakan bahwa luas lahan sempit yakni rata-rata 0,25 hektar, bibit unggul namun jumlah penggunaan masih dibawah standar, lebih banyak menggunakan tenaga kerja luar keluarga, petani dominan menggunakan pupuk anorganik, menggunakan pestisida untuk mengusir hama penyakit dan peralatan kerja yang sederhana. Penggunaan input usahatani belum optimal sehingga pengurangan atau penambahan ketersediaan input tidak akan mempengaruhi keuntungan total pada kondisi optimal. Pengaruh perubahan saat terjadi kenaikan dan penurunan harga input sebesar 3,25 persen tidak memperlihatkan perbedaan apabila dibandingkan dengan kondisi optimal awal.
\end{abstract}

Kata Kunci: Optimalisasi, Input, Bawang Merah, Program Linier, LINDO

\section{PENDAHULUAN}

Komoditas hortikultura merupakan jenis tanaman semusim yang banyak diusahakan di berbagai daerah, baik dari jenis sayuran, buahbuahan, maupun tanaman obat dan salah satunya adalah bawang merah (Allium 
ascolonium L). Tanaman bawang merah umumnya diusahakan oleh petani secara komersial yang sebagian besar atau seluruh hasil produksinya ditujukan untuk memenuhi permintaan pasar. Jumlah permintaan yang tinggi setiap tahunnya diiringi dengan tingginya tingkat konsumsi masyarakat menjadikan komoditas bawang merah ini menguntungkan jika diusahakan. Jumlah produksi dan tingkat kebutuhan nasional merupakan faktor determinan yang cukup kuat mempengaruhi keputusan untuk mendorong pengembangan dan peningkatan produksi di tingkat lokal.

Areal tanaman bawang merah di Propinsi Riau baru dibuka pada bulan Oktober 2013 di Kabupaten Kampar. Pada awal penanaman jumlah produksi bawang merah mencapai 12 ton dengan luas panen 3 hektar atau produktivitas sebesar 4 ton/hektar (Dinas Pertanian Tanaman Pangan dan Hortikultura Kabupaten Kampar, 2014). Nilai produksi dan produktivitas yang dihasilkan ini dianggap sebagai dasar untuk mengambil keputusan apakah potensi yang tersedia mampu menopang usaha komoditas ini di tahun-tahun mendatang atau tidak. Potensi pengembangan bawang merah di Kabupaten Kampar khususnya di Desa Sungai Geringging cukup luas yakni mencapai 40.684 hektar.

Beberapa input yang digunakan dalam memproduksi bawang merah yaitu lahan, tenaga kerja, bibit, pupuk, pestisida, dan peralatan. Lahan merupakan faktor produksi yang langka dan terbatas, baik sifat fisik dan kimia, yang akan mempengaruhi tingkat kesuburan dan produksi total usahatani (Widodo, 2007). Luas lahan garapan yang dimiliki petani bawang merah ini umumnya berukuran kecil yaitu kurang dari satu hektar, dan tenaga kerja yang diberdayakan masih banyak berasal dari luar keluarga. Bibit merupakan salah satu faktor penentu kualitas hasil produksi, oleh karenanya meskipun harga bibit tergolong mahal namun petani di Desa Sungai Geringging tetap menggunakan bibit unggul yang didatangkan langsung dari Brebes, Jawa Tengah. Mahalnya harga bibit menyebabkan jumlah penggunaan bibit antar petani bervariasi. Pupuk merupakan input usahatani yang penggunaannya harus optimal agar didapat produksi maksimal. Sahara, dkk (2017) meneliti bahwa untuk mendapatkan produksi maksimal tanaman ubi kayu di lahan kering perlu mengurangi jumlah pupuk SP-36 karena dianggap berlebih namun menambah pupuk Phonska karena jumlahnya belum optimal. pestisida juga masih digunakan ketika terjadi serangan hama penyakit. Peralatan produksi umumnya masih sederhana dan secara manual. Semua input yang digunakan tersebut masih terbatas jumlahnya sementara produksi tinggi sangat diharapkan oleh petani.

Berdasarkan uraian tersebut, maka penelitian ini dilakukan dengan tujuan untuk mengetahui penggunaan input usahatani, menganalisis penggunaan input usahatani agar mencapai kondisi optimal dan menganalisis pengaruh perubahan harga input terhadap solusi optimal pada usahatani bawang merah di Desa Sungai Geringging Kecamatan Kampar Kiri Kabupaten Kampar. Manfaat yang ingin diperoleh adalah sebagai kajian pustaka bagi pihak manapun yang ingin mendapatkan gambaran mengenai optimalisasi penggunaan input usahatani bawang merah, sumbangan pemikiran bagi petani untuk mengembangkan usahatani bawang merah sesuai standar umum budidaya dengan mengoptimalkan penggunaan input sehingga produksi dan pendapatan meningkat, dan informasi bagi instansi terkait dalam merumuskan arah pelaksanaan pembangunan subsektor tanaman hortikultura, khususnya pengembangan komoditas bawang merah di Kabupaten Kampar di masa datang.

\section{METODE PENELITIAN}

Penelitian ini menggunakan metode survei di Desa Sungai Geringging Kecamatan Kampar Kiri Kabupaten Kampar Propinsi Riau dengan alasan bahwa daerah ini merupakan sentra penanaman bawang merah di Kabupaten Kampar. Pengambilan sampel secara sensus, artinya seluruh populasi dijadikan sampel (Nazir, 2003) yaitu 40 petani. Data yang digunakan berasal dari data primer dan data sekunder. Data primer diperoleh dari petani bawang merah dengan menggunakan kuesioner, sedangkan data sekunder dari BPS dan instansi pemerintah terkait. Teknik pengumpulan data yang penulis gunakan pada penelitian ini antara lain observasi, dokumentasi, dan wawancara.

\section{Analisis Data}

Penggunaan input usahatani bawang merah di Desa Sungai Geringging yang meliputi luas lahan, jumlah tenaga kerja, jumlah 
penggunaan bibit, pupuk, pestisida, dan peralatan dianalisis secara deskriptif kualitatif. Data yang telah dikumpulkan ditabulasi sesuai dengan karakteristiknya input masing-masing kemudian dihitung nilai keseluruhan untuk memudahkan mendapatkan nilai rata-rata yang selanjutnya diinterpretasikan agar mudah dipahami pembaca.

Analisis optimalisasi menggunakan Linear programming (LP) yang merupakan salah satu teknik riset operasi metode matematika dalam mengalokasikan sumberdaya yang langka untuk mencapai tujuan (Render, 2012). Variabel keputusan yang dikendalikan oleh pengambil keputusan bertujuan untuk memaksimalkan atau meminimalkan kuantitas (laba atau biaya), fungsi tujuan umumnya untuk memaksimalkan tujuan jangka panjang dan fungsi kendala untuk mengetahui sampai dimana sasaran dapat dicapai. LP secara sederhana diformulasikan dalam persamaan matematis (Antara dan Suardika, 2014) sebagai berikut:
a. Fungsi tujuan
$\mathrm{Z}=\mathrm{C}_{1} \mathrm{X}_{1}+\mathrm{C}_{2} \mathrm{X}_{2}+\ldots \ldots \ldots . \mathrm{CnXn}$
$\mathrm{Z}=\sum_{j=1}^{n} C j X j$ untuk $\mathrm{j}=1,2,3, \ldots ., \mathrm{n}$
b. Fungsi kendala :
$a_{11} X_{1}+a_{12} X_{2}+\ldots \ldots \ldots .+a_{1 n} X_{n} \leq b_{1}$
$a_{21} X_{1}+a_{22} X_{2}+\ldots \ldots \ldots+a_{2 n} X_{n} \leq b_{2}$
$a_{m 1} X_{1}+a_{m 2} X_{2}+\ldots \ldots \ldots . .+a_{m n} X_{n} \leq b_{n}$
$\sum_{i=1}^{m} \operatorname{ajXj} \geq 0$, untuk $\mathrm{i}=1,2,3 \ldots, \mathrm{m}$
c. Asumsi
$X_{1}, X_{2}, \ldots . . X_{n} \geq 0$
$\mathrm{Xj} \geq 0$
Keterangan:
$\mathrm{Z}=$ Nilai fungsi tujuan
$\mathrm{C}=$ Koefisien fungsi biaya dan koefisien peubah pengambilan keputusan
$\mathrm{Xj}=$ Aktivitas/ variabel keputusan (yang ingin dicari)
aij = koefisien input-output dalam kendala ke-i untuk memperoleh satu satuan $\mathrm{Xj}$
bi = sumberdaya tersedia/ konstanta dari kendala ke-i

Proses perhitungan menggunakan program LINDO (Linear Interactive and Discrete Optimizer) dimana hasil analisis dapat berupa analisis primal, analisis dual, analisis sensitivitas, dan post optimal. Analisis Primal, memberikan informasi mengenai tingkat kegiatan terbaik dan menghasilkan tujuan yang maksimum dengan keterbatasan sumberdaya yang tersedia. Analisis Dual, adalah hubungan antara tingkat kegiatan optimal dengan keterbatasan sumberdaya yang dimiliki. Nilai slack/surplus menggambarkan jumlah kelebihan atau kekurangan pemanfaatan sumberdaya pada tingkat kegiatan optimal. Apabila nilai slack nol berarti sumberdaya tersebut habis terpakai (langka), sebaliknya jika nilai slack tidak sama dengan nol artinya sumberdaya tersebut tersedia dalam jumlah yang berlebih dan nilai slack menunjukkan jumlah kelebihan (surplus). Nilai bayangan (dual prices) berbanding terbalik dengan nilai slack yaitu sumberdaya yang langka nilai bayangannya tidak sama dengan nol. Sumberdaya yang menjadi kendala merupakan sumberdaya yang memiliki nilai bayangan tertinggi dan dapat menambah pendapatan bersih jika ketersediaannya ditambah satu satuan. Analisis Sensitivitas, memberikan informasi mengenai naik turunnya harga atau biaya kegiatan yang diperbolehkan agar tidak merubah hasil optimal dan perubahan kuantitas sumberdaya yang diperbolehkan sehingga hasil optimal tidak berubah.

Untuk mengetahui tingkat produksi dan penggunaan input produksi yang optimal sehingga keuntungan maksimum dapat dicapai maka fungsi tujuan harus ditentukan dahulu, kemudian menentukan fungsi pembatas atau kendala. Kendala yang digunakan dalam penyelesaian optimalisasi ini meliputi seluruh biaya untuk setiap penggunaan input produksi bawang merah. Fungsi kendala ditentukan atas dasar keterbatasan petani dalam menyediakan input untuk melakukan proses produksi.

Secara matematis program linier dalam penelitian ini adalah sebagai berikut:

Fungsi tujuan:

$$
\mathrm{Z}=\mathrm{C}_{1} \mathrm{X}_{1}+\mathrm{C}_{2} \mathrm{X}_{2}+\mathrm{C}_{3} \mathrm{X}_{3}+\mathrm{C}_{4} \mathrm{X}_{4}+\mathrm{C}_{5} \mathrm{X}_{5}
$$

Fungsi kendala:

$$
\begin{aligned}
& a_{11} X_{1}+a_{12} X_{2}+a_{13} X_{3}+a_{14} X_{4}+a_{15} X_{5} \leq b_{1} \\
& a_{21} X_{1}+a_{22} X_{2}+a_{23} X_{3}+a_{24} X_{4}+a_{25} X_{5} \leq b_{2} \\
& a_{31} X_{1}+a_{32} X_{2}+a_{33} X_{3}+a_{34} X_{4}+a_{35} X_{5} \leq b_{3} \\
& a_{41} X_{1}+a_{42} X_{2}+a_{43} X_{3}+a_{44} X_{4}+a_{45} X_{5} \leq b_{4} \\
& a_{51} X_{1}+a_{52} X_{2}+a_{53} X_{3}+a_{54} X_{4}+a_{55} X_{5} \leq b_{5}
\end{aligned}
$$

Keterangan:

$$
\begin{aligned}
\mathrm{Z}= & \text { pendapatan bersih petani dari } \\
& \text { optimalisasi penggunaan input } \\
\mathrm{Cjxj}= & \text { penerimaan petani dengan penggunaan } \\
& \text { input }
\end{aligned}
$$




$$
\begin{aligned}
& \mathrm{Cj} \text { = rata-rata keuntungan pertahun } \\
& \text { usahatani bawang merah } \\
& \mathrm{xj}=\text { jumlah bawang merah yang } \\
& \text { diproduksi pertahun } \\
& \text { a11...a15 = koefisien penggunaan tenaga kerja } \\
& \text { (HOK/Ha/Musim tanam) } \\
& \text { a21...a25 = koefisien penggunaan bibit } \\
& \text { (kg/Ha/Musim tanam) } \\
& \text { a31...a35 = koefisien penggunaan pupuk } \\
& \text { ( } \mathrm{kg} / \mathrm{Ha} / \mathrm{Musim} \text { tanam) } \\
& \mathrm{a} 41 \ldots \mathrm{a} 45=\text { koefisien penggunaan pestisida } \\
& \text { (lt/Ha/Musim tanam) } \\
& \text { a51...a55 = koefisien penggunaan peralatan } \\
& \text { (unit/Ha/Musim tanam) }
\end{aligned}
$$

Sedangkan untuk mengetahui pengaruh perubahan harga input bawang merah terhadap solusi optimal dilakukan secara deskriptif kuantitatif menggunakan analisis post optimal. Analisis Post Optimal digunakan untuk mempelajari nilai-nilai dari peubah pengambil keputusan dalam suatu model. Jika satu atau beberapa parameter model tersebut berubah maka kondisi optimal akan berubah. Analisis ini dilakukan setelah kondisi optimal awal sudah diketahui. Pada analisis post optimal akan dilakukan perubahan yang disebut skenario. Skenario yang dibuat dalam penelitian ini yaitu perubahan harga input bawang merah karena perubahan harga ini senantiasa berfluktuasi. Skenario 1 dilakukan dengan menurunkan harga input sebesar 3,25 persen dan skenario 2 adalah peningkatan harga input sebesar 3,25 persen. Penentuan nilai 3,25 persen didasarkan pada tingkat inflasi rata-rata yang terjadi pada tahun 2018 (BI, 2018).

\section{HASIL DAN PEMBAHASAN}

\section{Penggunaan Input Usahatani}

a. Luas Lahan, merupakan salah satu faktor produksi yang memiliki kontribusi besar terhadap usahatani. Besar kecilnya produksi usahatani dipengaruhi oleh luas lahan, namun bukan berarti semakin luas lahan maka semakin efisien lahan tersebut. Hasil penelitian menunjukkan bahwa luas lahan untuk usahatani bawang merah bervariasi, tetapi umumnya sebesar 0,25 hektar. Luas dan sempitnya lahan yang digunakan untuk menanam bawang merah disebabkan karena petani menanam tanaman lain pada lahan yang sama. Pada dasarnya petani memang memfokuskan pada penanaman bawang merah, namun untuk meningkatkan pendapatan rumahtangga maka petani melakukan diversifikasi atau menganekaragamkan jenis tanaman pada areal yang sama, yakni tanaman musiman lainnya, seperti padi, jagung, kacang-kacangan, dan tanaman sayuran lainnya.

b. Bibit, berperan untuk menunjang keberhasilan produksi terutama tanaman yang berasal dari bibit unggul atau bermutu tinggi. Disamping kualitas maka kuantitas bibit juga perlu diperhatikan. Penggunaan bibit yang terlalu banyak berdampak pada penurunan jumlah produksi karena jarak tanam yang rapat membuat tanaman tidak dapat tumbuh dengan baik (Rahayu dan Berlian, 2004). Jenis bibit yang digunakan pada usahatani bawang merah adalah varietas Brebes dan Bima. Hasil penelitian menunjukkan bahwa jumlah penggunaan bibit yang dominan digunakan petani adalah $120 \mathrm{~kg} /$ garapan yang dilakukan oleh 12 petani dengan luas lahan 0,25 hektar. Penggunaan bibit yang direkomendasikan untuk 1 hektar lahan adalah 800-1.200 kg, artinya jumlah penggunaan bibit bawang merah masih di bawah anjuran. Hal ini dikarenakan luas lahan budidaya bawang merah masih skala kecil dan tingginya harga bibit yaitu Rp 35.000/kg.

c. Tenaga Kerja, merupakan sumberdaya usahatani yang sangat berperan dalam kegiatan produksi. Umumnya tenaga kerja yang digunakan berasal dari dalam keluarga dan luar keluarga. Penggunaan tenaga kerja ditentukan oleh pasar tenaga kerja yang juga dipengaruhi oleh tingkat upah dan harga hasil produksi. Tenaga kerja dalam keluarga lebih banyak digunakan karena berfungsi sebagai penekan biaya tenaga kerja (Tohir, 1983). Pengusaha cenderung akan menambah tenaga kerja selama produk marginal lebih tinggi daripada biaya yang dikeluarkan (Nopirin, 1996). Berdasarkan penelitian terhadap tenaga kerja untuk seluruh tahapan kerja, mulai dari pengolahan tanah, penanaman, pemupukan, penyiangan, penyemprotan dan pemanenan, lebih banyak menggunakan tenaga kerja luar keluarga yaitu 37,97 HOK/Ha/Musim tanam sedangkan tenaga kerja dalam 
keluarga hanya 23,98 $\mathrm{HOK} / \mathrm{Ha} / \mathrm{Musim}$ tanam. Penggunaan tenaga kerja luar keluarga yang lebih besar dikarenakan usahatani bawang merah membutuhkan tenaga kerja cukup banyak, terutama pada tahapan pemupukan dan penyiangan.

d. Pupuk, bertujuan untuk mengisi kekurangan unsur hara dalam tanah sehingga kebutuhan tanaman terpenuhi, tanaman tumbuh subur sehingga produksi per satuan luas lahan akan meningkat. Pemberian pupuk yang seimbang akan menghasilkan produksi yang optimal (Kasirah, 2007). Pupuk yang digunakan terdiri dari pupuk organik (pupuk kandang) dan pupuk anorganik (Dolomit, Urea, $\mathrm{KCl}$, NPK dan Bayfolan). Pupuk yang paling banyak digunakan oleh petani adalah pupuk kandang yaitu $45,88 \%$ dari total penggunaan pupuk baik pupuk organik maupun anorganik. Hal ini dikarenakan pupuk kandang banyak digunakan diawal penanaman dibandingkan dengan pupuk kimia. Sementara pupuk anorganik yang paling banyak digunakan adalah Dolomit $(31,18 \%)$ karena berfungsi untuk menetralisir $\mathrm{pH}$ tanah.

e. Pestisida, untuk mencegah kerusakan tanaman dan kegagalan panen akibat serangan hama dan penyakit maka perlu adanya pengendalian hama dan penyakit secara terpadu. Penggunaan pestisida harus tepat dosis dan tepat waktu untuk mengurangi dampak negatif terhadap lingkungan (Sulistiyono, 2004). Penggunaan pestisida dianggap sebagai cara yang paling mudah, efektif dan paling banyak digunakan petani untuk mengendalikan hama dan penyakit. Beberapa pestisida yang dipakai pada usahatani bawang merah yaitu Gramoxon, Drusband, Furadan dan Antracol. Berdasarkan penelitian diketahui bahwa jenis pestisida yang banyak digunakan adalah Furadan sebesar 78,66\% karena pada awal penanaman pestisida ini berfungsi untuk mengusir serangga kecil yang ada di dalam tanah dan pestisida yang paling sedikit digunakan adalah Drusband sebesar 6,18\%.

f. Peralatan, dalam hal ini alat dan mesin, digunakan petani untuk mempermudah proses budidaya tanaman bawang merah sehingga secara tidak langsung mempengaruhi lama atau cepatnya pekerjaan usahatani diselesaikan. Beberapa peralatan yang umum digunakan dalam usahatani bawang merah adalah gembor, angkong, cangkul, pisau kecil, sabit, ember, sprayer, selang air dan kored. Jumlah penggunaan peralatan berkaitan dengan nilai penyusutan yang mempengaruhi besaran biaya dan pendapatan usahatani tersebut. Berdasarkan hasil penelitian diketahui bahwa peralatan yang lebih banyak digunakan adalah ember sebanyak 4 unit atau $17,26 \%$ dari keseluruhan peralatan. Penggunaan selang untuk menyiram tanaman adalah 22,13 meter yang airnya diperoleh langsung dari saluran irigasi semi teknis yang ada di lokasi penanaman.

\section{Tingkat Optimal Penggunaan Input}

Berdasarkan hasil perhitungan LINDO, kondisi optimal penggunaan input usahatani bawang merah pada lima macam jenis input yaitu tenaga kerja dalam keluarga, bibit, pupuk, pestisida dan peralatan menghasilkan keuntungan atau pendapatan bersih sebesar $\mathrm{Rp}$ 10.346.560. Hasil tersebut menunjukkan bahwa penggunaan input usahatani belum optimal. Pendapatan bersih usahatani bawang merah di Desa Sungai Geringging secara aktual yakni Rp 6.797.456, ini artinya apabila dibandingkan dengan hasil optimal maka keuntungan total yang diterima petani dapat ditingkatkan sebesar Rp 3.549.104 atau 0,34 persen. Nilai Reduced Cost pada masing-masing penggunaan input dapat dilihat pada Tabel 1 berikut:

Tabel 1. Nilai Reduced Cost hasil Optimalisasi Penggunaaan Input Usahatani Bawang Merah Desa Sungai Geringging Kecamatan Kampar Kiri Kabupaten Kampar

\begin{tabular}{lrr}
\hline \multicolumn{1}{c}{ Input } & \multicolumn{1}{c}{$\begin{array}{l}\text { Value } \\
\text { (unit) }\end{array}$} & \multicolumn{1}{c}{$\begin{array}{c}\text { Reduced Cost } \\
\text { (Rp) }\end{array}$} \\
\hline TKDK & 1,00 & -1.085 .000 \\
Bibit & 1,00 & -7.272 .125 \\
Pupuk & 1,00 & -1.489 .638 \\
Pestisida & 0,00 & -461.915 \\
Peralatan & 1,00 & -499.800 \\
\hline
\end{tabular}


Berdasarkan Tabel 1 terlihat bahwa reduced cost bernilai minus atau lebih kecil dari nol maka dapat diartikan adanya penambahan keuntungan yang diterima petani apabila menambah penggunaan input sebesar 1 unit. Besaran nilai penambahan keuntungan tersebut adalah sama dengan nilai reduced cost-nya. Untuk pestisida, keuntungan usahatani akan didapat jika penggunaan input ini dalam kondisi tetap. Kondisi optimal dapat dicapai jika dilakukan perubahan pada alokasi penggunaan input usahatani, dimana perubahan tersebut dapat berupa penambahan atau pengurangan penggunaan input (Ritonga, 2008).

Selanjutnya analisis dual untuk mengetahui penilaian terhadap sumberdaya dengan melihat slack or surplus dan nilai dualnya. Nilai dual (dual price/shadow price) menunjukkan perubahan yang terjadi pada fungsi tujuan apabila sumberdaya berubah satu satuan sehingga dapat membedakan apakah sumberdaya yang dimiliki bersifat langka (pembatas) atau sebaliknya. Nilai slack or surplus dan nilai dual pada masing-masing kendala terlihat pada tabel berikut:

Tabel 2. Nilai Slack or Surplus dan Dual Penggunaan Input Usahatani Bawang Merah Desa Sungai Geringging Kecamatan Kampar Kiri Kabupaten Kampar

\begin{tabular}{lrr}
\hline \multicolumn{1}{c}{ Kendala } & \multicolumn{1}{c}{$\begin{array}{c}\text { Slack or } \\
\text { Surplus }\end{array}$} & Dual Price \\
\hline TKDK & 6,880 & 0,000 \\
Bibit & $3.189,000$ & 0,000 \\
Pupuk & $1.419,310$ & 0,000 \\
Pestisida & 4,159 & 0,000 \\
Peralatan & 6,660 & 0,000 \\
\hline
\end{tabular}

Tabel 2 memperlihatkan input tenaga kerja, bibit, pupuk, pestisida dan peralatan memiliki nilai slack yang lebih besar dari nol, artinya faktor-faktor kendala tersebut merupakan kendala tidak aktif. Pengurangan atau penambahan ketersediaan input-input tersebut tidak akan mempengaruhi keuntungan total pada kondisi optimal.

Penggunaan tenaga kerja pada keadaan normal adalah 23,98 HOK sementara nilai slack pada kendala tenaga kerja lebih besar dari nol yaitu $6,88 \mathrm{HOK}$, artinya ketersediaan tenaga kerja berlebih sebesar nilai slack-nya tersebut. Penggunaan tenaga kerja dalam keluarga lebih sedikit dibandingkan tenaga kerja luar keluarga sehingga kelebihan jumlah tenaga kerja dalam keluarga tidak akan berpengaruh pada perubahan kondisi optimal usahatani bawang merah. Nilai slack bibit, pupuk, pestisida dan peralatan bernilai lebih besar dari nol artinya penggunaan input usahatani tersebut telah berlebih sehingga perlu untuk dikurangi agar tidak terjadi penurunan jumlah produksi dan pemborosan biaya.

Pada optimalisasi penggunaan input usahatani bawang merah ini juga dapat diketahui hasil analisis sensitivitas yang terbagi atas analisis sensitivitas dengan melakukan perubahan pada fungsi tujuan dan perubahan Righthand Side Ranges (RHS) fungsi kendala. Perubahan ini dapat berupa penambahan atau pengurangan jumlah penggunaan input, seperti pada tabel berikut:

Tabel 3. Analisis Sensitivitas Koefisien Fungsi Tujuan Usahatani Bawang Merah di Desa Sungai Geringging Kecamatan Kampar Kiri Kabupaten Kampar

\begin{tabular}{lrrr}
\hline \multirow{2}{*}{ Variabel } & \multicolumn{3}{c}{ Objective Coefficient Ranges } \\
\cline { 2 - 4 } & $\begin{array}{c}\text { Current } \\
\text { coefficient }\end{array}$ & $\begin{array}{c}\text { Allowable } \\
\text { increase }\end{array}$ & $\begin{array}{c}\text { Allowable } \\
\text { decrease }\end{array}$ \\
\hline TKDK & 1.085 .000 & 0,000 & Infinity \\
Bibit & 7.272 .125 & Infinity & 7.272 .125 \\
Pupuk & 1.489 .638 & Infinity & 1.489 .638 \\
Pestisida & 461.915 & 0,000 & Infinity \\
Peralatan & 499.800 & Infinity & 499.800 \\
\hline
\end{tabular}

Berdasarkan tabel 3 bahwa nilai allowable increase fungsi tujuan yang dapat dinaikkan sampai batas tak terhingga (infinity) adalah pada variabel bibit, pupuk dan peralatan. Sementara nilai fungsi tujuan yang dapat diturunkan sampai batas tak terhingga adalah tenaga kerja dalam keluarga dan pestisida. Hal ini menunjukkan bahwa penambahan jumlah tenaga kerja dalan keluarga dan penambahan pestisida akan dapat menurunkan keuntungan usahatani.

Nilai batas penurunan ini menunjukkan bahwa tingkat keuntungan akan bertambah jika koefisien fungsi tujuan turun lebih kecil atau sama dengan nilai batas tersebut. Jika perubahan koefisien fungsi tujuan melebihi nilai allowable decrease maka tingkat produksi optimal akan berubah. Besarnya nilai penurunan keuntungan tersebut sama dengan selisih 
keuntungan kondisi awal dengan kondisi setelah perubahan dikalikan tingkat produksi optimal. Analisis sensitivitas juga dapat dilakukan pada kendala pembatas, seperti pada tabel berikut:

Tabel 4. Analisis Sensitivitas Fungsi Kendala Usahatani Bawang Merah di Desa Sungai Geringging Kecamatan Kampar Kiri Kabupaten Kampar

\begin{tabular}{lrrr}
\hline \multirow{2}{*}{ Variabel } & \multicolumn{3}{c}{ Righthand Side Ranges(RHS) } \\
\cline { 2 - 4 } & $\begin{array}{c}\text { Current } \\
\text { RHS }\end{array}$ & $\begin{array}{c}\text { Allowable } \\
\text { increase }\end{array}$ & $\begin{array}{r}\text { Allowable } \\
\text { decrease }\end{array}$ \\
\hline TKDK & 23,98 & Infinity & 6,88 \\
Bibit & 7066,00 & Infinity & $3.189,00$ \\
Pupuk & 2565,34 & Infinity & $1.419,31$ \\
Pestisida & 58,13 & Infinity & 4,15 \\
Peralatan & 19,41 & Infinity & 6,66 \\
\hline
\end{tabular}

Pada Tabel 4 terlihat bahwa seluruh nilai RHS fungsi kendala tidak memiliki batasan penambahan (infinity). Artinya jumlah tenaga kerja, bibit, pupuk, pestisida dan peralatan tidak akan merubah nilai dari fungsi tujuan atau jika ketersediaan input-input tersebut dinaikkan berapapun tidak akan merubah tingkat produksi optimal karena nilai dual-nya ssama dengan nol.

Sebaliknya, seluruh nilai RHS fungsi kendala mempunyai batasan penurunan dengan nilai tertentu dan akan menyebabkan nilai fungsi tujuan berubah sebesar nilai dual-nya. Apabila penurunan ketersediaan input tenaga kerja dalam keluarga, bibit, pupuk, pestisida dan peralatan melebihi batas sensitivitasnya maka tingkat produksi optimal akan berubah.

\section{Pengaruh Perubahan Harga Input Bawang Merah Terhadap Solusi Optimal}

Pengaruh perubahan harga input pada usahatani bawang merah menggunakan analisis post optimal yaitu untuk mengetahui sejauh mana usahatani bawang merah mampu bertahan dan berproduksi secara optimal terhadap perubahan harga input. Analisis post optimal membagi kondisi dalam dua skenario yakni skenario 1 pada kenaikan harga input dan skenario 2 pada saat penurunan harga input.

\section{Skenario 1 (Kenaikan Harga Input)}

Harga jual input yang berfluktuasi dapat mempengaruhi keuntungan yang diterima petani sehingga petani harus meningkatkan efisiensi produksi agar tetap bertahan di pasar. Kenaikan dan penurunan harga input menyebabkan petani mengurangi atau menambah jumlah penggunaan input tersebut yang pada akhirnya berakibat pada jumlah produksi yang dihasilkan. Skenario 1 yakni pada saat kenaikan harga input tenaga kerja dalam keluarga, bibit, pupuk, pestisida dan peralatan sebesar 3,25 persen maka petani memperoleh pendapatan bersih sebesar $\mathrm{Rp}$ 10.773.130. Apabila dibandingkan dengan tingkat keuntungan hasil analisis optimalisasi versi awal maka nilai keuntungan ini masih belum optimal dan hanya terjadi peningkatan sebesar 0,04 persen. Hasil optimalisasi skenario 1 dapat dilihat pada tabel berikut:

Tabel 5. Nilai Reduced Cost Hasil Optimalisasi Kenaikan Harga Input Usahatani Bawang Merah Desa Sungai Geringging Kecamatan Kampar Kiri Kabupaten Kampar (Skenario 1)

\begin{tabular}{lrr}
\hline \multicolumn{1}{c}{ Input } & \multicolumn{1}{|}{$\begin{array}{l}\text { Value } \\
\text { (unit) }\end{array}$} & $\begin{array}{c}\text { Reduced Cost } \\
\text { (Rp) }\end{array}$ \\
\hline TKDK & 1,00 & -1.120 .263 \\
Bibit & 1,00 & -7.508 .469 \\
Pupuk & 1,00 & -1.630 .149 \\
Pestisida & 0,00 & -384.828 \\
Peralatan & 1,00 & -514.253 \\
\hline
\end{tabular}

Berdasarkan Tabel 5 memperlihatkan nilai solusi optimal yang tidak jauh berbeda dari solusi optimal versi awal reduced cost yang bernilai minus atau lebih kecil dari nol. Sehingga terdapat penambahan keuntungan yang diterima petani apabila menambah penggunaan input tenaga kerja dalam keluarga, bibit, pupuk dan peralatan masing-masing setiap 1 unit sebessar nilai reduced cost-nya. Sementara nilai slack or surplus dan nilai RHS masih sama dengan nilai optimalisasi versi awal.

\section{Skenario 2 (Penurunan Harga Input)}

Pada skenario 2 yakni pada saat penurunan harga input tenaga kerja dalam keluarga, bibit, pupuk, pestisida dan peralatan sebesar 3,25 persen maka petani memperoleh pendapatan bersih sebesar Rp 10.096.600. Apabila dibandingkan dengan tingkat keuntungan hasil analisis optimalisasi versi awal maka nilai keuntungan ini masih belum optimal dan mengalami penurunan sebesar 0.02 persen. 
Hasil optimalisasi skenario 2 dapat dilihat pada Tabel 6. Nilai solusi optimal yang diperoleh tidak jauh berbeda dari solusi optimal versi awal dan solusi optimal skenario 1 dimana nilai reduced cost yang bernilai minus atau lebih kecil dari nol. Sehingga terdapat penambahan keuntungan yang diterima petani apabila menambah penggunaan input tenaga kerja dalam keluarga, bibit, pupuk dan peralatan masing-masing setiap 1 unit sebessar nilai reduced cost-nya.

Tabel 6. Nilai Reduced Cost Hasil Optimalisasi Penurunan Harga Input Usahatani Bawang Merah Desa Sungai Geringging Kecamatan Kampar Kiri Kabupaten Kampar (Skenario 2)

\begin{tabular}{lcr}
\hline \multicolumn{1}{c}{ Input } & $\begin{array}{l}\text { Value } \\
\text { (unit) }\end{array}$ & \multicolumn{1}{c}{$\begin{array}{c}\text { Reduced Cost } \\
(\mathrm{Rp})\end{array}$} \\
\hline TKDK & 1,00 & -1.049 .738 \\
Bibit & 1,00 & -7.035 .780 \\
Pupuk & 1,00 & -1.527 .525 \\
Pestisida & 0,00 & -360.601 \\
Peralatan & 1,00 & -483.557 \\
\hline
\end{tabular}

\section{DAFTAR PUSTAKA}

Antara M, Suardika N. 2014. Optimalisasi Sumberdaya pada Sistem Usahatani Lahan Kering di Desa Kerta, Gianyar Bali: Pendekatan Linear Programming. Jurnal Ekonomi Kuantitatif Terapan, Vol 7 (1) $35-51$

Bank Indonesia. 2018. Laporan Inflasi (Indeks Harga Konsumen) Berdasarkan Perhitungan Inflasi Tahunan. Jakarta

Dinas Pertanian Tanaman Pangan dan Hortikultura Kabupaten Kampar. 2014. Jumlah Produksi Bawang Merah di Kabupaten Kampar. Bangkinang

Kasirah. 2007. Sistem Informasi Pemupukan Lahan Pertanian. Seminar Nasional
Aplikasi Teknologi Informasi (SNATI) ISSN: 1907-5022. Yogyakarta

Nazir M. 2003. Metode Penelitian. Ghalia Indonesia. Jakarta

Nopirin. 1996. Ekonomi Moneter Buku 2 Edisi 1. BPFE. Yogyakarta

Rahayu E, Berlian Nur VA. 2004. Bawang Merah. Penebar Swadaya. Jakarta

Render B, Stair JR and Hana. 2012. Quantitatif Analysis for Management. Pearson Education.New Jersey

Ritonga EZ. 2008. Optimalisasi Penggunaan Faktor-faktor Produksi pada Peternakan Ayam Ras Pedaging kelompok Bina Usahatani Muslim (KBTM) Desa Cilodong Depok. Program Sarjana Ekstensi Manajemen Agribisnis Istitut Pertanian Bogor

Sahara D, Agus S. 2017. Optimasi Penggunaan Input Produksi Usahatani Ubi Kayu pada Lahan Kering di Jawa Tengah. Jurnal Pengkajian dan Pengembangan Teknologi Pertanian, Vol 20 (2): 91-100

Sulistiyono L. 2004. Dilema Penggunaan Pestisida dalam Sistem Pertanian Tanaman Hortikultura di Indonesia. Sekolah Pasca Sarjana Institut Pertanian Bogor

Tohir AK. 1983. Seuntai Pengetahuan Tentang Usahatani Indonesia. Bina Aksara. Jakarta

Widodo AS. 2007. Optimalisasi Penggunaan Sarana Produksi dalam Usahatani Padi Organik Terpadu di Kecamatan Paliyan Kabupaten Bantul. Jurnal Ilmu-Ilmu Pertanian Universitas Muhammadiyah Yogyakarta, Vol 16 (2): 91-102 